\title{
Employees' Educational Composition and Firm's Learning: Evidence from Manufacturing Industries in Iran
}

\author{
Mohammad Ali Feizpour, Mansour Mahinizadeh, Marjan Habibi, and Wen-Shai Hung
}

\begin{abstract}
Learning can be analyzed at the individual level in addition to firm'slevel. But, with a closer look, learning by firms depends on the composition of employees which can be apart in terms ofeducational levels. In Iran, educational level of manufacturing firms is divided to seven groups, includingilliterate, not holding high school diploma, holding high school diploma, associate, bachelor, master and doctorate. In this regards, with combining these levels, two groups of higher education and non-higher education can be obtained and solearning is expected to be diverse in these two groups.Accordingly, this article focuses on investigating the effect of higher education level on learning, using data in the Non-metallic mineral products manufacturingfirms as one of the main manufacturing industries in Iran. With investigating two distributions, lognormalandPareto, the results of this study have shown that a certain threshold of percentage of higher educated employees for affecting on firm learning is needed. In particular, firms with more than 30 percent of employees affects firm's learning and follows Pareto distribution.From policy point of view, this finding indicates that soft business support, instead of hard business support, including employee's education can be considered as one of the most industrial policy in the case of developing countries.
\end{abstract}

Index Terms-Employees education composition, pareto distribution, firm's learning, manufacturing industries, Iran.

\section{INTRODUCTION}

Human capital plays an essential role in economic developments. In particular, it is important to know about the relations between firm's development and using higher educated employees,so that the composition of labor forces with various educational levels, which distributed differently throughout various economic firms and sectors, has an important effect on firm learning. Accurate policy in improving development of firms requires being aware of the needs of economic firms for higher educated employees. Educational levels' effect on firm learning has been neglected since there is lack of research in this field. So, the aim of this paper is examining the issue that the percentage of higher educated employees is importantfor firm's learning and hence, by providing more and more higher educated employees can firms follow a certain distributional pattern. Althoughinvestigating this issue can be performed

Manuscript received January 10, 2014; revised March 20, 2014. The paper is the result of some parts of research titled "Estimating Learning Curve in Iranian Manufacturing Industries" with the support of Iran National Science Foundation.

Mohammad Ali Feizpour, Mansour Mahinizadeh, and Marjan Habibiare are with the Department of Economics, Business School, Yazd University, Yazd, Iran (e-mail: m.a.feizpour@yazd.ac.ir, Mmahinizadeh@yazd.ac.ir, m.habibi@stu.yazd.ac.ir).

Wen-Shai Hung is with the Department of Business Administration, Providence University, Taiwan (e-mail: wshung@pu.edu.tw). for all economic sectors, but the emphasis of this paper is on manufacturing industries, because of the fact that development pivot in Iran is based on this sector. Among Iranian manufacturing industries, which are classified to 23 industries in terms of International Standards Industrial Classification (ISIC) of the economic activities, the Nonmetallic mineral products manufacturingindustry (MNP here after) is the most important industry in Iran. It should be noted thatthis industry among other industries can be discovered with the precise look at the number of employees (14 percent of total employees in 2005) and number of firms (22 percent of total firms in 2005). Hence, this paper attempts to examine the effect of employees'educational composition on firm's learning in 2005, using lognormalandParetodistributions.

The paper is organized as follows: after introduction, Section II discusses some results previously obtained in the literature. Section III describes distributions which will be used in this paper. Section IV demonstrates the results and finally, Section V concludes.

\section{LITERATURE}

The vast body of literature has focused on the firm size distribution. In fact, most of them take into account the lognormal and Paretodistributions to obtain the best functional fit to the empirical one. As a pioneering study on this issue, Gibrat [1] demonstrated that firm size can be represented by lognormal distribution as a result of the Law of Proportionate Effect (LPE here after). In fact, LPEstates that firm size follows a random walk and hence, the growth of firms is erratic and independent of size. In addition, the size distribution of firms is constant over time and is almost lognormal. This issue has been studied extensively in economics literature. Several researches in empirical studiesshow that the size distribution of firm is highly skewed and lognormal distribution is a good fit to the empirical one (ex, [2]-[5]). On the other hand,the actual size distribution may changes gradually over time and may differ from a lognormal distribution [6].Furthermore, these rules are robust over time and resistant to economic and political changes [7].

Running alongside these studies of the lognormal, there has been an empirical investigation of Pareto distributions. Indeed, Pareto law is a well-known feature of firm size distribution which demonstrates that frequency of firms in a population above a certain size is inversely proportional to the firm size [8]. Recently, researches have shown that firm size distribution can be approximated of Pareto distribution (ex. [9]-[12]). In general, several statistical rules in analyzing industrial data have been emerged: distribution of firm sizes is definitely skewed to the right and shows thick 
long tails. In addition, shape of the distribution is not general.

As it is known, most of the literature has fitted firms' size by means of the lognormal and Pareto, since they both show a satisfactory descriptive power. In addition, many studies considered the determinants of shaping the size distribution.

Among several studies in industrial economies on the determinants of firm size distribution, some of them considered the effect of age.In general, as the age of the firms increases, the size distribution shifts to the right, the left tails become thinner and the right tail thicker, with a clear decrease of the skewness [13]. In another study on Italian firms, the findings by Cabral and Mata [13] have been confirmed, using the generalized Beta distribution of the second kind. In this regards, the size distribution of Italian firms is approximated by a Singh-Maddala distribution for the youngest firms and a Fisk one for the oldest ones [14].

Reference [15], in regards to the effect of mergers and acquisitions (M\&As) on the firm size distribution, shows that M\&As shift the firm size distribution towards larger sizes, so that size distribution becomes more concentrated around the mean, less skewed to the right hand side, and thinner at the tails as a whole. As a result, M\&Aslead to the departures from lognormality, suggesting that the change in the size distribution is almost entirely due to the external growth of the firms.

Reference [16] investigated the effect of learning on the size distribution of firms. In fact, they show that in various industries in terms of the kind of technology, the speed of convergence varies based on different processes of learning. In the most technologically advanced industries in which entrants tend to invest in their capacity more gradually, after exploring their efficiency level with respect to their competitors, a convergence towards the lognormal distribution emerges with the passing of time. And conversely, in the most traditional industries the same tendency is less marked.

However, despite the widespread literature on the determinants of firm size distribution, there is lack of attention to the effect of education on firm size distribution. So, the main novelty of this paper is the analysis of the firm size distribution by the composition of employeesin terms of higher education at firm levels. Particularly, we want to establish whether the firm size distribution varies as the percentage of higher educated employees increase.

\section{Distribution OF Firm Sizes: A Closer Perspective}

The debate on firm size distribution has been started since pioneering study by Gibrat [1], demonstrating the LPE. As mentioned above, based on this law, the growth of each firm is independent of firm size and lognormally distributed. This feature is shown in (1), where $x(t)$ is the size of firm in time $t$ and $\varepsilon(t)$ is a random variable distributed independently and identically, stating the proportionate effect between $x(t)$ and $x(t-1)$ with the mean $\mu$ and variance $\sigma^{2}$.

$$
\begin{gathered}
x(t)=[1-\varepsilon(t)] x(t-1)= \\
x(0)[1+\varepsilon(1)]\left[\begin{array}{c}
1+ \\
\varepsilon(2)
\end{array}\right] \ldots[1+\varepsilon(t)]
\end{gathered}
$$

Taking logarithms of (1) with approximating $\log [1+$ $\varepsilon(t)] \cong \varepsilon(t)$, it leads to $\log x(t)=\log x(0)+\sum_{t=1}^{T} \varepsilon(t)$. Since $\log x(0)$ in comparison with $\log x(t)$ is too small, using central limit theorem, as $t \rightarrow \infty, \log x(t)$ can be approximated to normal distribution with mean $\mu_{t}$ and variance $\sigma_{t}^{2}$ [17]. Hence, the probability density function of lognormal distribution is:

$$
f(x)=\frac{1}{\sigma \sqrt{2 \pi} x} e^{-(\log (x)-\mu)^{2} /\left(2 \sigma^{2}\right)}
$$

In addition to lognormal distribution, firm size distribution can be represented with the Pareto distribution. This distribution is obtained in many studies. In this regards, Pareto law demonstrate that the frequency of firms above the certain threshold is inversely related to the firm size. This feature is shown based on the right cumulative distribution function in (3):

$$
F(x)=\operatorname{Pr}\left(X \geq x_{i}\right)=x_{0}^{\alpha} x_{i}^{-\alpha}
$$

where $x_{0}$ is the scale parameter that is the minimum of size and $\alpha$ is the shape parameter. In addition, the probability density function is:

$$
f(x)=\alpha \frac{x_{0}^{\alpha}}{x^{\alpha+1}}, \quad x \geq x_{0}>0
$$

As can be explained, most of the literature in this field of research has been used the lognormal and Pareto distribution to evaluate and compare the firm size distribution. Hence, this paper uses these two distributions for investigating the effect of employees' education composition on the firm size distribution.

\section{DISCUSSION}

Various proxies can be used to classify the firms according to their size. Despite all these proxies, we use the higher education criteria in our analysis. The data series used are those firms existing in the MNP as one of the most important industries in Iran in 2005. Higher education in this paper is described as employees with the degree of associate, bachelor, master and doctorate. The number of firms in the MNP industry is 3315, in which 1665 firms have no higher educated employees and so 1660 firms can be considered in our analysis (50 percent).

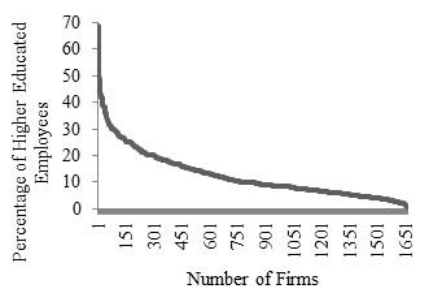

Fig. 1. Percentage of higher educated employees in year 2005.

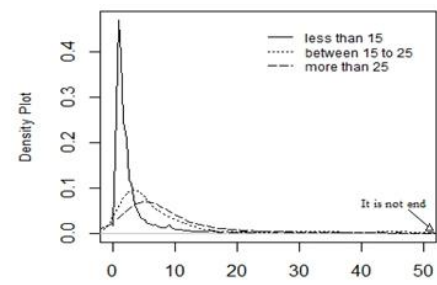

Fig. 2. Probability density plot of different size classes. 
Fig. 1 reports the percentage of higher educated employees. As shown on this figure, the percentage of employees with higher education goes from a minimum of
0.5 percent to a maximum of 69 percent, indicating large number of firms with lower percentage of higher educated employees and small number of firms with higher one.
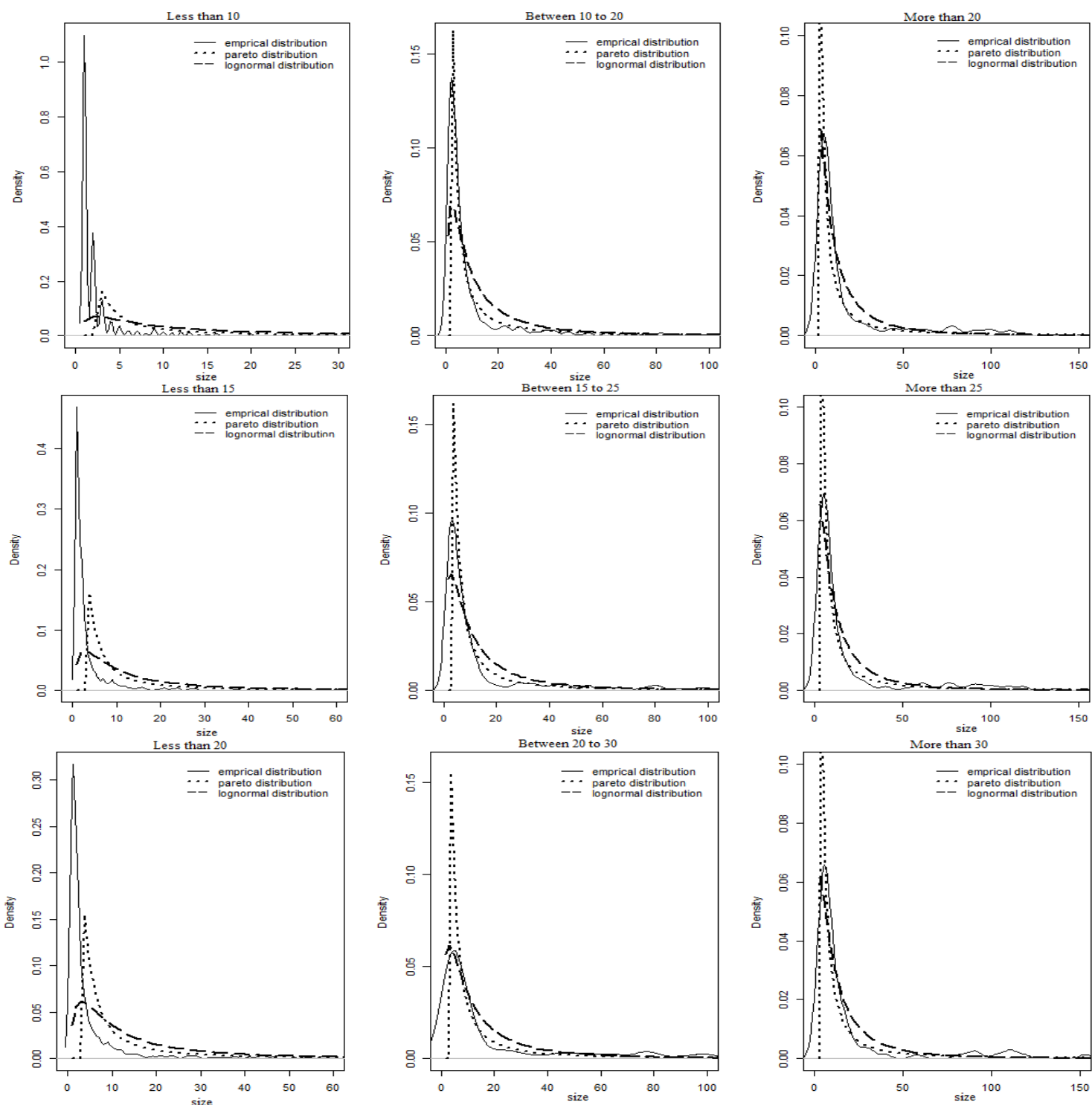

Fig. 3. plots of size distribution along with lognormal and Pareto distributions for different classes.

TABLE I: CHARACTERISTICS OF FIRMS BASED ON DIFFERENT GROUPS

\begin{tabular}{ccc}
\hline \hline classification & Number of firms & Number of employees \\
\hline Less than 10 & 818 & 2308 \\
Less than 15 & 1156 & 5665 \\
Less than 20 & 1356 & 8524 \\
$10-20$ & 538 & 6216 \\
$15-25$ & 327 & 5535 \\
$20-30$ & 219 & 4686 \\
More than 20 & 304 & 6868 \\
More than 25 & 177 & 4192 \\
More than 30 & 85 & 2182 \\
Total & 1660 & 15392 \\
\hline \hline
\end{tabular}

We have divided these firms into several groups to obtain a certain threshold of percentage of higher educated employees. These groups along with the size distribution of firms in this year are shown in Table I. It should be noted that as percentage of higher educated employees increased, the number of firms decreased sharply. For this, 30 percent of higher educated employees are considered as the last class.

In addition, Fig. 2 shows the size distribution of firms by the percentage of higher educational levels with the focus of just three classes including less than 15, between 15-25 and more than 25 percent of higher educated employees. In particular, we show the probability density plot of the size in 2005. It's interesting to see how the size distribution shifts to the right as the percentage of higher educated employees increase. It can be explained by the fact that the quantity of higher educated employees may be effective to the firms' learning.

Despite the graphical analysis by density plots, this issue should be statistically investigated for the more precise results.

As regards the fitting of the size distribution, based on what is explained in section III, we plot the density of the size distribution in Fig 3. Based on different groups of size classes along with the lognormal and Pareto distributions in 
the MNP industry and in terms of percentage of higher education levels. Set of plots in Fig 3 shows as the percentage of higher educated employees increase, the empirical distributions fit better and better, so that the groups of more than 20, more than 25 and more than 30 percent of higher educated employees converting to the lognormal and Pareto distributions.

For the precise examination of the effect of higher education levels on firm learning, in this paper, the parameters of the lognormal and Pareto distributions estimated using maximum likelihood estimator. Accordingly, the results have shown in Table II and Table III. In order to establish whether the fitted distributions correctly model our data, we use the standard goodness of fit test. In particular, we have chosen the Kolmogrovsmirnov (KS) test. The KS statistics for a given cumulative distribution function $F(x)$ is:

$$
D_{n}=\operatorname{Sup}_{x}\left|F_{n}(X)-F(X)\right|
$$

where

$F_{n}(X)=\frac{1}{n} \sum_{i=1}^{n} I_{X_{i}<x}$ is the empirical cumulative distribution function. The null hypothesis that the sample comes from $F(X)$ is rejected at level of $\alpha$ for $\sqrt{n} D_{n}>K_{\alpha}$, where $K_{\alpha}$ is obtained from $\operatorname{Pr}\left(K \leq K_{\alpha}\right)=1-\alpha$, according to the Kolmogrov distribution [14].

TABLE II: ESTIMATION OF LOGNORMAL DISTRIBUTION AND GOODNESS OF

\begin{tabular}{lcccc}
\multicolumn{5}{c}{ FIT TEST } \\
\hline \hline classification & $\hat{\sigma}$ & $\hat{\mu}$ & KS & $P$-value \\
\hline Less than 10 & 0.792 & 0.519 & 0.333 & 0 \\
Less than 15 & 1.004 & 0782 & 0251 & 0 \\
Less than 20 & 1.088 & 0.941 & 0.206 & 0 \\
10 to 20 & 1.161 & 1.581 & 0.131 & 0 \\
15 to 25 & 1.174 & 1.994 & 0.133 & 0 \\
20 to 30 & 1.212 & 2.233 & 0.133 & 0 \\
More than 20 & 1.185 & 2.275 & 0.141 & 0 \\
More than 25 & 1.133 & 2.321 & 0.164 & 0 \\
More than 30 & 1.106 & 2.383 & 0.166 & 0.02 \\
\hline \hline
\end{tabular}

TABLE III: ESTIMATION OF PARETO DISTRIBUTION AND GOODNESS OF FIT

\begin{tabular}{lcccc}
\multicolumn{5}{c}{ TEST } \\
\hline \hline classification & $\hat{\alpha}$ & $\hat{x}_{0}$ & KS & $P$-value \\
\hline Less than 10 & 1.928 & 1 & 0.589 & 0 \\
Less than 15 & 1.279 & 1 & 0.469 & 0 \\
Less than 20 & 1.064 & 1 & 0.401 & 0 \\
10 to 20 & 0.632 & 1 & 0.242 & 0 \\
15 to 25 & 0.768 & 2 & 0.180 & 0 \\
20 to 30 & 0.649 & 2 & 0.141 & 0 \\
More than 20 & 0.632 & 2 & 0.161 & 0 \\
More than 25 & 0.818 & 3 & 0.124 & 0.01 \\
More than 30 & 0.779 & 3 & 0.109 & 0.48 \\
\hline \hline
\end{tabular}

Based on Tables II and III which consist of estimated parameters and the goodness of fit test,only the class of more than 30 percent of higher educated employees has the $\mathrm{P}$-value more than 0.05 percent, and it can be deducted that in the five percent level the empirical distribution fit with the Pareto distribution. Overall and with considering the obtained results from investigating the size distribution based on employees' educational levels, employing labor forces with higher education do not affect the process of convergence to the lognormal or Pareto distributions, unless the percentage of higher educated employees (of total employees) is more than 30 . In particular, a certain quantity of higher educated employees is required for each industry to be effective for the process of learning.

\section{CONCLUSION}

This paper provides new empirical evidence on the effect of employees' educational composition on the shape of firm size distribution and thereupon, on firm's learning. To do so, we classified firms into several groups and tried to find a distributional pattern. Using lognormal and Pareto distributions and based on the maximum likelihood estimator, we found that as the percentage of higher educated employees increases, the widespread variance of the size reduces due to the process of learning. The most important result found in this paper is the threshold for using higher educated employees in each firm to be effective in convergence to the learning processes. In particular, each firm is required to employ more than 30 percent of higher educated employees to be helpful in obtaining a certain distributional structure. For the investors of industrial sectors, this quantity should be taken into account in time of entry and for the future years. In addition, from the policy perspective, soft business support can be considered as one of the most industrial policy at least in the case of developing countries.

\section{REFERENCES}

[1] R. Gibrat, Les InegalitesEconomiques, Sirey, Paris, 1931.

[2] P. E. Hart and S. J. Prais, "The analysis of business concentration," Journal of Royal Stat. Soc., vol. 119, pp. 150-91, 1956.

[3] H. Simon and C. P. Bonini, "The size distribution of business firms," American Economic Review, vol. 48, pp. 607-617, 1958.

[4] J. Sutton, "Gibrat's legacy," Journal of Economic Literature, vol. 35, pp. 40-59, 1997.

[5] S. Hymer and P. Pashigian, "Firm size and rate of growth," Journal of Political Economy, vol. 70, pp. 556-569, 1962.

[6] B. H. Hall, "The relationship between firm size and firm growth in the United States manufacturing sector," Journal of Industrial Economics, vol. 35, pp. 583-606, 1987.

[7] R. L. Axtell, "Zipf distribution of US firm sizes," Science, vol. 293, pp. 1818-1820, 2001.

[8] O. Marsili, "Technology and the size distribution of firms: Evidence from Dutch Manufacturing," Review of Industrial Organization, vol. 27, pp. 303-328, 2005.

[9] J. Steindl, Random Processes and the Growth of Firms, New York: Hafner, 1965.

[10] Y. Ijiri and H. Simon, Skew Distributions and the Sizes of Business Firms, New York, Amsterdam: North-Holland, 1977.

[11] J. Ramsden and G. Kiss-Haypal, "Company size distribution in different countries," Physica A, vol. 277, pp. 220-227, 2000.

[12] E. Gaffeo, M. Gallegati, and A. Palestrini, "On the size distribution of firms: Additional evidence from the G7 countries," Physica A, vol. 324, pp. 117-123, 2003.

[13] L. Cabral and J. Mata, "On the evolution of the firm size distribution: Facts and theory," American Economic Review, vol. 93, pp. 10751990, 2003.

[14] P. Cirillo, "An analysis of the size distribution of Italian firms by age," Physica A, vol. 389, pp. 459-466, 2010.

[15] E. Cefis, O. Marsili, and H. Schenk, "The effects of mergers and acquisitions on the firm size distribution," Journal of Evolutionary Economics, vol. 19, pp. 1-20, 2009.

[16] F. Lotti and E. Santarelli, "Industry dynamics and the distribution of firm sizes: A non-Parametric approach," Southern Economic Journal, vol. 70, pp. 443-466, 2004. 
[17] S. H. Kang, Z. Jiang, C. Cheong, and S. Yoon, "Changes of firm size distribution: The case of Korea," Physica A, vol. 390, pp. 319-327, 2011.

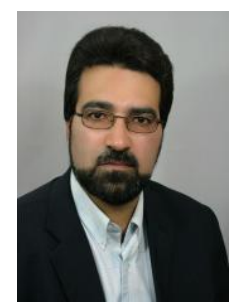

Mohammad Ali Feizpour was born in Maybod, Yazd, Iran, on April 4, 1967. He has finished his diploma in Maybod in 1985 and after that started bachelor's degree in economics in Shiraz University. Feizpour's master degree was in economic regional planning in Tarbiyat Modares University, Tehran in 1990 and after that his Ph.D degree in industrial economics in the Newcastle University, Newcastle upon Tyne, UK in 2002.

Ali was a lecturer at Yazd University, Iran since 1991. Dr. Feizpour has published more than 40 papers in scientific journals and presented more than 100 papers in national and international conferences. His interest is mainly in the field of industrial and labour economics. He is now as assistant professor at Yazd University in Iran.

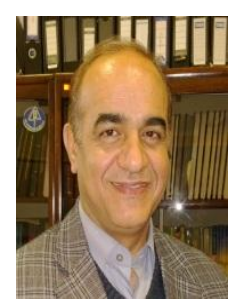

Mansour Mahinizadeh was born in Yazd, Iran, on June 25,1965 . He has received his bachelor's degree in economics from Mazandaran University in 1989. Mahinizadeh's master degree was in economic development and planning in Tehran University in 1986. He is a faculty member of Yazd University since 1993. Also, he has studied his Ph.D in Esfahan University from 2002 to 2011.

Dr. Mahinizadeh has published three papers in scientific journals and presented 7 papers in national conferences. His interest is mainly in the field of industrial economics, growth economics and also urban and regional economics. He is now as assistant professor at Yazd University in Iran.

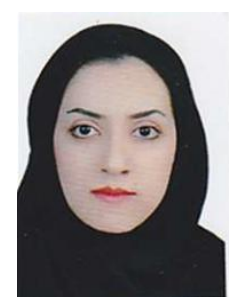

in Iran.

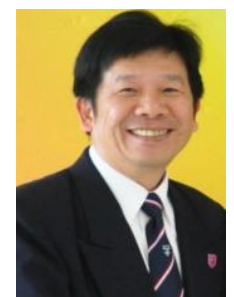

Marjan Habibi grew up in Gorgan, Iran on November 6, 1986. She has finished her diploma in Gorgan in 2003 and also she received her bachelor's degree in economics from payam-e-Noor University of Gorgan in 2009. Marjan now is a MA student at Yazd University with an emphasis in Industrial Economics. Though her research interests are relatively broad, she is currently involved in research concerning firm size distribution and its determinants presented more than 30 papers in the international conferences. His interests are focused on the fields, including labour economics, social welfare, and public policy. He is now as an associate professor at Providence University in Taiwan. 